\title{
AN INEQUALITY INVOLVING A TRIANGLE AND AN INTERIOR POINT AND ITS APPLICATION
}

\author{
TATYANA SOROKINA AND SHANGYOU ZHANG
}

Abstract. Let $\mathbf{x}_{0}$ be an interior split point in the triangle $T:=\left[\mathbf{x}_{1}, \mathbf{x}_{2}, \mathbf{x}_{3}\right]$. By $\alpha_{i j}$ we denote the angle $\widehat{\mathbf{x}_{0}, \mathbf{x}_{i}, \mathbf{x}_{j}}, i \neq j$. We show that

$$
\cos \alpha_{12} \cos \alpha_{23} \cos \alpha_{31}+\cos \alpha_{21} \cos \alpha_{32} \cos \alpha_{13}>0 .
$$

Additionally, we use this inequality to prove uniqueness and existence of a conforming quadratic piecewise harmonic finite element on the Clough-Tocher split of a triangle.

Mathematics subject classification (2010): 51N20, 65N30.

Keywords and phrases: Triangle, interior point, inequality, product of cosines, finite element, harmonic, Clough-Tocher.

\section{REFERENCES}

[1] P. Alfeld, AND T. Sorokina, Linear Differential Operators on Bivariate Spline Spaces and Spline Vector Fields, BIT Numerical Mathematics, 56, 1(2016), 15-32.

[2] S. C. BRENNER AND L. R. SCOTT, The mathematical theory of finite element methods, Third edition, Texts in Applied Mathematics, 15, Springer, New York, 2008.

[3] M.-J. Lai And L. L. Schumaker, Spline functions on triangulations, Cambridge University Press, Cambridge, 2007.

[4] D. S. Mitrinović, J. E. PeČArić And V. Volenec, Recent Advances in geometric Inequalities, Kluwer Academic Publishers, The Netherlands, 1989.

[5] S. ZHANG AND T. SoRoKInA, Conforming harmonic finite elements on the Hsieh-Clough-Tocher split of a triangle, submitted. 